\title{
HISTÓRIAS DE HIGIENIZAÇÃO PELO TRABALHO: CRIANÇAS PARANAENSES NO NOVECENTOS
}

\author{
Vera Regina Beltrão Marques*
}

\begin{abstract}
RESUMO: A cruzada higienista empreendida no começo do século XX não poupou os infantes. Ao contrário, fez deles alvo importante de sua investida. $\mathrm{E}$ os homens de ciência foram pródigos ao enunciar estratégias para transformá-los de despossuídos em futuros cidadãos laboriosos. Fim do século XX. Outros homens de ciência arregaçam as mangas em nova cruzada: erradicar a labuta das crianças. Este artigo pretende refletir acerca do trabalho infantil à luz das normas higienizadoras do início do século.
\end{abstract}

Palavras-chave: História da educação e do trabalho. Trabalho infantil. Higiene. Infância.

\section{STORIES OF HYGIENIZATION THROUGH LABOUR: Children from Paraná In the XIX ${ }^{\mathrm{TH}}$ Century}

ABSTRACT: The hygienic crusade undertaken at the beginning of the $\mathrm{XX}^{\text {th }}$ Century also involved the children. In fact, it took them as its major target. Scientists were lavish when it came to strategies that would turn these destitute into future toiling citizens. By the end of the XX ${ }^{\text {th }}$ Century, other scientists launched a new crusade: eradicating children's labor. The present paper reflects on children labor in the light of hygiene rules of the beginning of that century.

Key words: Education and labor history. Children labor. Hygiene. Childhood.

Doutora em História Social pela Universidade Estadual de Campinas (UNICAmp) e professora na Universidade Federal do Paraná (UFPr). E-mail: verabm@ufpr.br 


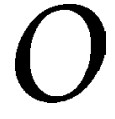

trabalho infantil é proibido no país. Assim reza a Constituição Brasileira em vigor desde 1988. Organismos internacionais, tais como Organização Internacional do Trabalho (OIT) e Fundo das Naçóes Unidas para a Infância (UNICEF), amparam e pressionam as nações a erradicarem as ocupaçōes laborais dos pequenos. Todavia, o Brasil apresenta altos índices de crianças empenhadas no ganho do pão de cada dia. E mesmo havendo campanhas e incentivos para reverter a dura realidade traduzida pelos dados do PNAD 1999, continuamos nos destacando: ocupamos posição muito incômoda no ranking dos países que sacrificam seus cidadãos do futuro.

Se hoje parece haver consenso na condenação do trabalho dos infantes, nem sempre foi assim.

Nos inícios do século passado, homens de ciência acreditavam que o trabalho se constituiria em antídoto aos perigos decorrentes do ócio e do vício que "rondavam" crianças pobres desocupadas.

Sim, pois na cruzada civilizatória a que se lançaram médicos, pedagogos, filantropos, juízes, delegados de polícia, empresários, dentre outros, tratava-se de constituir cidadãos afinados com os novos símbolos da modernidade. A indústria, a cidade, o progresso, a tecnologia e a ciência estavam na ordem do dia. Fazia-se mister construir a sociedade do trabalho.

Segundo os higienistas, crianças desprovidas, vagando pelas ruas, redundariam em adultos de "índole indefinida, mentalidade inconstante, vícios políticos e sociais" prontas a qualificar-se nas denominadas "classes perigosas". Nunca seriam os futuros trabalhadores ordeiros, disciplinados, demandados pelo capital.

Qual teria sido o contributo das propostas higienizadoras na permanência de uma cultura do trabalho infantil?

Embora muitas sejam as causas da manutenção da ocupação laboral de crianças na sociedade atual, delimitou-se como objetivo abordar os desdobramentos das normas higienizadoras. Para tanto, investigaram-se as notícias estampadas nas páginas diárias das gazetas paranaenses, ao longo dos anos da década de 1990. Números, imagens, análises, que tratavam de trazer ao leitor a crueza do mundo do trabalho enfrentado por esta "petizada", foram aproximadas ao discurso dos homens da higiene, dos começos do século XX. 


\section{Uma prática antiga: pequenos no trabalho}

Enquanto perdurou a escravidão, os princípios impressos à educação das crianças passaram ao largo dos pequenos escravos que, a não ser em casos esporádicos e "de carona", acompanhavam seus sinhozinhos nos primeiros estudos.

Desde muito cedo, às crianças escravas foi reservado o aprender a trabalhar a fim de sobreviver, identificadas que estavam como fonte de trabalho e renda. Assim, por volta dos 7 a 8 anos de idade, já deveriam prestar serviços regulares como transportar trouxas de roupa ou tripés de tabuleiro e não mais acompanhar os filhos dos senhores ou mesmo suas mães a brincar. Como salienta Mariano Pereira dos Santos, ex-escravo nas terras do Paraná: "Criança que podia reunir aquelas raizinhas de toco, montuava, trabaiava. A que não podia, eles [chefes] iam criando até a idadinha de trabaiá no regime deles. E o pai não tinha direito mais. Nem o pai, nem a mãe (...)" (apud Mello, 1989, p. 24).

A exploração laboral dos pequenos escravos era não só de conhecimento, como objeto de regulamentação dos legisladores de então. Em 1825, uma medida trabalhista da autoria de José Bonifácio de Andrada e Silva proibia o trabalho insalubre e fatigante aos menores de 12 anos (Passeti, in: Del Priori, 1996, p. 149). Legislação essa que se constituiu em letra morta.

Nas primeiras etapas da industrialização, a situação só fez agravar-se: crianças e adolescentes encontravam-se na labuta cotidiana das fábricas ao arrepio das vozes de médicos e sanitaristas que, embora defendendo as virtudes moralizadoras do trabalho, escancaravam as precárias condiçôes de vida e trabalho vividas pelos pequenos. Conforme atesta Antonio F. Bandeira Júnior, em 1901 era considerável o número de crianças a partir de 5 anos de idade ocupadas em atividades fabris na cidade de São Paulo.

A entrada de crianças no mercado de trabalho concretizou um dos grandes anseios do empresariado, pois ao possibilitar a diminuição dos custos de produção contribuiu para aumentar a acumulação do capital. Crianças-operárias recebiam salários irrisórios para operar máquinas projetadas para adultos nas quais produziam tanto quanto estes. Porém não esqueçamos o detalhe: empresários importaram máquinas adaptadas aos pequenos para que, nelas, eles pudessem docilmente render mais. 
Meninos e meninas representavam $15 \%$ da mão-de-obra empregada na década de 1890 em São Paulo, trabalhando em indústrias do vestuário, de fósforos, de fumo, têxteis, alimentícias, fundiçôes, oficinas mecânicas, fábricas de móveis, afora as serrarias, tipografias e olarias. Somente no setor têxtil, as crianças representavam $25 \%$ da força de trabalho ocupada (Moura, in: Del Priore, 1996, p. 114).

Porém, as conseqüências para esses pequenos foram extremamente danosas. A partir de 1891, o governo provisório da República, almejando dificultar que milhares de crianças fossem exploradas, estabeleceu medidas objetivando regrar o trabalho daquelas empregadas em estabelecimentos industriais, na capital federal. Certamente as autoridades passavam a cogitar sua intenção de coibir tais abusos. Além do mais, doenças e mortes redundariam num futuro próximo em diminuição do contingente de trabalhadores adultos. E braços úteis de onde sairiam? Como referia o parlamentar Deodato Maia:

os edifícios de nossas fábricas, com pouquíssimas exceções, são velhos pardieiros ajeitados para esta ou aquela indústria; mas nas instalaçōes e adaptações "à la diable", para tudo se olha menos para a saúde do operário. As crianças ali vivem na mais detestável promiscuidade; são ocupadas nas indústrias insalubres e nas classificadas de perigosas, falta-lhes ar e luz; o menino operário raquítico e doentezinho deixa estampar na fisionomia aquela palidez cadavérica e aquele olhar sem brilho - que denuncia o grande cansaço e a perda gradativa da saúde. (Maia, 1912, p. 6)

No Paraná, nos idos do Oitocentos, o trabalho infantil também se fazia notar. Em relatórios de governo, as autoridades provinciais reclamavam que os filhos de imigrantes não iam à escola por encontrarem-se às voltas com o cultivo da erva-mate, tratando de incrementar a economia doméstica. Pois nas colônias paranaenses, "o lote da família era trabalhado pelo próprio colono, bem como por sua mulher e filhos, e o produto deste trabalho era vendido nos mercados próximos. Nestas pequenas propriedades não havia empregados, escravos ou agregados" (Miranda, 1978, p. 161).

Em Curitiba, nos inícios da produção fabril, em uma importante fábrica de fósforos, "moças e meninas encontravam trabalho certo e lucrativo", anunciava Paraná (1899, p. 492). Ou, ainda: “Todos os necessitados, inclusive mulheres, velhos e crianças, encontram ali [fábricas] ocupações compatíveis com as forças e aptidões de cada um" (idem, p. 480). 
Assim fosse em instalações industriais e oficinas, ou em atividades agrícolas, lá estavam as crianças dispensando quase todas as horas do seu dia na faina laboral, demonstrando com isso que o trabalho infantil vem permanecendo como mácula em nossa história.

\section{Trabalho: a higienização das crianças pobres}

A exploração do trabalho infantil atingiu tamanha magnitude nos inícios do Novecentos que crianças adoeciam, morriam ou eram mutiladas no ambiente fabril. A imprensa operária paulista pintava com tons fortes a "tortura brutal imposta através da maquinaria", chamando a atenção para situações rotineiras como a "odiosa exploração à qual estão subjugadas as nossas crianças em prejuízo da sua saúde e da sua inteligência”. As lideranças operárias temiam que o trabalho precoce arrefecesse as energias dos pequenos a ponto de tirar-lhes a garra para a luta. Também não davam trégua aos pais, pois estes se rendiam pelo "miserável auxílio financeiro que a criança pode trazer à família, permitindo consciente ou inconscientemente que a mesma seja sacrificada à ganância de um explorador assassino" (Bertucci, 1997, p. 137).

Em 1917, o Centro Libertário de São Paulo cria o "Comitê popular de agitação contra a exploração dos menores nas fábricas" com o intuito de enfrentar a situação. Em notícias estampadas nos jornais, acusavam-se os proprietários de indústrias de exporem crianças aos riscos dos ambientes de trabalho. O caso de Vittorio Marcari, de 14 anos de idade, era mais um dentre tantos que o jornal $O$ Combate anunciava como vítima de acidente em uma fábrica de móveis (Moura, in: Del Priore, 1999, p. 280). Ou a denúncia, em 1917, na qual um dos sócios de uma fábrica de vidros em Curitiba fora acusado de atentar "contra o pudor de diversas menores operárias" (idem, ibid., p. 284).

Eram tantos e tão veementes os protestos vindos de diferentes setores da sociedade que leis foram aprovadas no intuito de conter a exploração do trabalho dos infantes. Porém, os industriais, capitaneados pelos paulistas, não esmoreceram. Tanto que Jorge Street durante as discussões do Código do Trabalho deixava claro: "Tenho na fiação de juta, cerca de cento e oitenta crianças, empregadas unicamente no conjunto da movimentação dos pequenos carretéis destinados a receber o fio, na carga e descarga desses carretéis nas máquinas de fiar". Trabalho esse, segundo ele, "muito leve e fácil", não 
demandava nenhuma aprendizagem e dependendo da "lei" aprovada poderia tornar-se mais vantajoso se executado por adultos, uma vez que os pequenos só poderiam trabalhar metade da jornada diária de 10 horas (Moura, 1988). ${ }^{1}$

Blefava Jorge Street. Aos industriais não interessava divulgar o quanto lhes era significativo contar com o trabalho dos infantes. Segundo o Censo de 1920, por exemplo, os operários adultos recebiam, em média, $22 \%$ a mais que as trabalhadoras e $130 \%$ acima dos ganhos das crianças, por tarefas muito semelhantes (Pires, 1988, p. 89).

E mais, esses empresários consideravam-se ajustados aos princípios civilizatórios: oportunizavam aos rebentos a pedagogia da fábrica, garantindo o trabalhador do futuro no extenuante labor de cada dia. $\mathrm{Na}$ ótica deles, escola para pobres iniciava-se no meio fabril; fora dele havia ócio, vício e delinqüência. Tomavam para si o discurso da higiene no tocante à regeneração pelo trabalho que demarcava projetos concebidos na tentativa de instaurar a ordem burguesa nos espaços urbanos (Costa, 1989; Cunha, 1986; Machado et al., 1978).

Se médicos higienistas denunciavam a exploração das crianças nas fábricas, pois impediria os pequenos de tornarem-se fortes trabalhadores no futuro, paradoxalmente viam o labor normalizado, metodizado funcionando como uma espécie de ortopedia social.

Ortopedia na qual o trabalho se pautava como eixo articulador. Ao unir os homens de ciência, de várias instituições, mantinha o objetivo maior: instituir a república brasileira higienizada. A higiene, plasmada pelo trabalho, marcaria o discurso da medicina, da psiquiatria, da educação, das relações de trabalho, da constituição das famílias no espaço urbano. Ao serem detectados "desvios" como os manifestos por crianças pobres, desprotegidas moral e materialmente, que sem ocupação vagassem pelas cidades, buscavam prontamente formas de inseri-los em instâncias disciplinares. Infância:

Pronunciava-se A. Gonçalves no I Congresso de Proteção à

Ah! Coraç̧ôes de pais, de mães, de esposos,

Salvai este pequeno rebotalho,

Fazei que o braço, hoje estendido à esmola,

Forte, amanhã, estenda-se ao trabalho! (1926, p. 458) 
Como esta ortopedia social se construía no Paraná? O processo modernizador chegara a Curitiba no início do Novecentos. Rocha Pombo realça-o ao reconhecer como suntuosa a cidade, na qual despontavam avenidas e boulevards. A iluminação elétrica fazia-se notar e linhas de bonds cortavam a cidade, ao passo que veículos variados trafegavam diariamente. "Há plena atividade, dentro do quadro urbano, mais de 300 fábricas e oficinas e no município todo, perto de 600. Já se funde em Curitiba tão perfeitamente como no Rio. Já se grava e já se fazem, em suma, todos os trabalhos de impressão tão bem como os melhores da Europa" (1930, p. 141).

Os jornais, no entanto, permitiam antever o que Rocha Pombo não revelava: imigrantes pobres, ex-escravos, desempregados, desocupados também ocupavam esse espaço urbano suntuoso. Crianças abandonadas, ou não, perambulavam pelas ruas. Pobres, doentes, famintas denunciavam tudo aquilo que era importante ocultar: desordem e vadiagem.

No imaginário burguês, a cidade moderna capitalista precisava apresentar-se plena de racionalidade, normalidade e disciplina. Havia de se criar essa modernização urbana em Curitiba. E tirar visibilidade das classes pobres aparecia como primeiro passo. Ameaçadoras e perigosas, representavam um empecilho à constituição da força de trabalho necessária ao processo capitalista em curso.

Crianças pauperizadas a perambular pela cidade, ocupando-a como espaço alternativo de sobrevivência, não escapavam da mira de policiais, juízes ou médicos.

Transformar alguns em aprendizes marinheiros, por exemplo, encaminhando-os para Paranaguá foi uma estratégia utilizada tanto por juízes quanto por policiais, desde o Oitocentos, no intuito de gerenciá-los, tornandos-os úteis a si e à nação. Porém outras instituiçōes de "seqüestro" também foram idealizadas, fossem disciplinares ou de correção.

Em 1912, uma Escola Premunitória era pensada pela polícia como interesse do estado ao "evitar que perambulem pela via pública pequenos mendigos, que cedo ou tarde penetrarão nas trevas da delinqüência, começando pelos pequenos crimes até chegarem à degradação máxima" (Relatório de Chefe de Polícia, apud De Boni, 1987, p. 92).

O chefe de polícia dava conta de esclarecer o papel de disciplinamento assumido e exercido pela corporação policial. Em 
consonância com os princípios higienizadores, as escolas premunitórias pretendiam-se também espaços de recuperação, ou regeneração de futuros criminosos.

Já o delegado de polícia Moreira Garcez, ao detectar o aumento da criminalidade infantil em Curitiba, entende que, sem hábitos de trabalho e sem instrução, inúmeras crianças constituirão legiões de criminosos, cabendo ao estado adotar meios de prevenção e repressão.

Impõe-se, portanto, a necessidade urgente e imprescindível da criação de um instituto disciplinar, destinado a incutir hábitos de trabalho, a educar e fornecer instrução literária e profissional, esta última de preferência agrícola, aos maiores de 9 anos e menores de 14 que obrarem com discernimento; aos maiores de 14 anos e menores de 21, condenados por infração do Art. 399 do Código Penal e Art. 2 do Decreto Federal (...). (Relatório de Chefe de Polícia, 1917, apud Karvat, 1998, p. 131)

O pedagogo A. Gonçalves explicava que, nas grandes capitais, infantes pobres ou abandonados passavam por várias gradações:

Se iniciam na função de camelôs, passam à venda dos jornais, e chegam à pivetes perigosos, capazes de toda a sorte de degradações (...). A criação de "Institutos Disciplinares", "Casas para a infância desamparada", ou "Patronatos" pode perfeitamente remover tal perigo e, quiçá, garantir para os seres infelizes um futuro (...). (1926, p. 457)

Sim, pois o

aliciamento da legião infantil para a grande campanha sanitária de cujo sucesso depende, indiscutivelmente, a própria vida da Nação, seria um passo considerável para a vitória. O Brasil precisa urgentemente do auxílio da legião infantil para ter no futuro os homens que saibam compreender a grandeza da nossa terra e a magnitude dos seus destinos. (Revista Médica do Paraná, 1933, p. 224)

A inauguração da Escola Agronômica do Paraná foi saudada com pompa e circunstância. O Patronato Agrícola, criado com a Escola, era destinado exclusivamente às classes pobres e visava "a educação moral, cívica, física e profissional de menores despossuídos e, daqueles que, por insuficiência da capacidade de educação na família, forem postos, por quem de direito, à disposição da Escola Agronômica". Esse instituto de "assistência, proteção e tutela moral de menores" recorria ao efeito do trabalho agrícola, "sem outro intuito que não o de utilizar sua ação educativa e regeneradora, com o fim de dirigir e orientar, até incorporá-los no meio rural" (apud Karvat, 1998, p. 134). 
Assim, segregar socialmente crianças pauperizadas, recolhendo-as em instituiçôes disciplinares na Curitiba suntuosa e moderna do século passado parece ter sido a fórmula encontrada para tirá-los das ruas. Educá-los implicava incutir-lhes o amor ao trabalho, o respeito à hierarquia e à ordem, o apego à civilização e a todas as máximas apregoadas pela moral burguesa. Ensinar "disciplinas", eis o mote das ações pedagógicas cujos propósitos não visavam a alterar as condiçóes sociais de vida dos pequenos.

Educá-los pelo e para o trabalho, procedendo à higienização social dos excluídos, ensinando-os a bem viver em sociedade, buscaria, ao fim e ao cabo, construí-los à imagem de bons trabalhadores. O que implicava: alterar hábitos, costumes e modos de ser e estar; inseri-los no tempo e no espaço da produção; incutir o hábito do fazer, do realizar racionalmente tarefas cotidianas desenvolvidas por meio de técnicas pedagógicas, cuidadosamente elaboradas que, para além de educar, servissem para adestrar, controlar. Enfim, cabia incorporá-los no mundo das práticas higienizadoras e moralizantes (Marques, 1994).

O trabalho desempenhava a função de moralizar a criança, além de prepará-la para a "servidão voluntária" como ressaltava La Boétie (1987). Pois a assimilação de valores da classe a que deveriam servir estava na ordem do dia e visava a incluí-la "futuramente" na sociedade dos cidadãos paranaenses probos e serviçais.

$\mathrm{Na}$ década de 1930, a educação moral intensifica seus tentáculos na higiene mental. Como salienta Costa (1981), os psiquiatras da Liga Brasileira de Higiene Mental (LBHM) acreditaram no mito da ciência psiquiátrica universal que, sob forte influência dos postulados totalitários advindos da Itália e Alemanha, sofria inflexão, estendendo-os "para todos os domínios da vida social" (p. 40). Até então, à LBHM "competira a educação higiênica, física e moral dos indivíduos, tornando-os fortes, sadios e aptos para o trabalho (...)" (Arquivos da LBHM, apud Costa, 1981), sem comprometer-se com postulados de "prevenção eugênica" vinculados à psiquiatria nazista.

Discípulos de Nina Rodrigues exercendo atividade na medicina legal endossaram esse discurso da ortopedia social, pois estreitas eram suas ligaçóes com a higiene mental dos anos 30. Ao atuar baseados na convicção de que o conhecimento do corpo humano e de seus determinantes são fundamentais para o entendimento das relaçôes em sociedade, vários deles destacaram-se ao estabelecer ilações entre crianças pobres/crianças abandonadas e criminalidade. Es- 
tudando espaços institucionais especiais, como o Instituto de Pesquisas Juvenis e o Serviço Social de Assistência e Proteção aos Menores, localizados em São Paulo, ou o Laboratório de Biologia Infantil no Instituto de Identificação do Rio de Janeiro, esses médicos emitiam pareceres que reforçavam esses supostos vínculos (Corrêa, in: Freitas, 1997).

Leonídio Ribeiro, aluno dileto de Afrânio Peixoto, a par da nova ciência, a "pedagogia terapêutica", idealizada por seguidores de Cesare Lombroso ${ }^{2}$ e também denominada de "medicina pedagógica"3 pelos alemães, chamava a atenção para o que denominava "sinais de alarme" das predisposições infantis. Segundo ele, "na criança de um ano é, às vezes, possível já reconhecer o futuro criminoso. É na primeira infância, ou na puberdade, que se revelam as primeiras tendências para as atitudes anti-sociais, que se concretizam e agravam progressivamente, sob a influência do ambiente" (Corrêa, in: Eulalio et al., 1982).

A tarefa ficaria principalmente a cargo das professoras, quando os infantes freqüentassem a escola, pois pais "desagregados, desonestos, alcoolizados, em constantes desavenças domésticas", como assinalavam os higienistas mentais, não seriam capazes de educar seus filhos, quiçá reconhecer neles os sinais de alarme propiciadores da medicalização. A escola, as autoridades policiais e judiciárias teriam papel de destaque nesses encaminhamentos (Ramos, s/d.).

Crianças pobres, no “ambiente desfavorável das ruas”, tornaram-se alvo natural das campanhas preventivistas. Precárias condições de saúde e educação logo foram definidas e diagnosticadas como predisposição biológica ao crime, a "inclinação natural" estabelecida por Lombroso. Clínicas de eufrenia ${ }^{4}$ foram abertas, cidades de menores ${ }^{5}$ projetadas, não logrando, como assinala Marisa Corrêa, senão produzir socialmente a figura do menor abandonado.

Ser reconhecida como criança menorizada se tornou questão de inserção social: menores eram filhos de trabalhadores imigrantes, ex-escravos, desempregados. Sim, porque a infância não poderia ser descrita no singular. Não havia a criança-padrão. Havia crianças ricas, pobres, abandonadas, órfãs, infratoras. E crianças pobres "recuperáveis" tinham a chance de educarem-se para o trabalho nas instituições reformadoras, alegavam os higienistas. $\mathrm{O}$ disciplinamento, a normalização, implicava iniciá-las no aprendizado de algum ofício (Cunha, 2000). 
Fins do século XX. Outros tempos, novas transformações no mundo do trabalho. O imperativo de constituir o mercado da força de trabalho no país já vai longe. O esforço dos higienistas em (con)formar trabalhadores saudáveis, moral e fisicamente, não está mais em voga. $\mathrm{O}$ ensino de ofícios às crianças pobres, intransigentemente defendido como proposta política de criação do espírito da ordem e cumprimento do dever, foi paulatinamente cedendo lugar à formação daqueles que a psicotécnica indicava como os mais "aptos" (Antonacci, 1985; Tenca, 1985; Cunha, 2000). Assistência, proteção e tutela moral de menores via efeito do trabalho regenerador com intuito de constituir bons trabalhadores sofreram transformações. Em nossos dias, a questão crucial é posta em outros termos.

Trata-se de normatizar, porém às avessas do discurso higienizador. A docilidade e a disciplina do operador laborioso apregoadas pelos higienistas desdobraram-se em novas exigências. O trabalhador atual deve apresentar como primeiro quesito "educação básica", o que implica ter pelo menos oito anos de escolarização. Ademais, serão exigidas dele relações entre o trabalho, a ciência e a cultura que lhe permitirão unificar o pensar com o fazer (Leite, 1994). Já não basta saber reproduzir o aprendizado da disciplina.

O ensino aligeirado, fragmentado, cuja maior preocupação residia em adestrar física e moralmente para o trabalho repetitivo, no qual dominava uma só técnica e um mesmo gesto, foi superado. Exige-se um trabalhador criativo e competitivo (Weinstein, 2000). Crianças já não são consideradas aptas a exercer toda e qualquer atividade. Ao contrário, o trabalho infantil encontra-se proscrito e banido em diversos ramos.

A par das novas exigências, a labuta na rua não cobra competência mínima, nem cumpre a letra da lei. Assim os pequenos aí se localizam, "formando-se" no trabalho-escola dos semáforos, das praças e avenidas. E todo o dia, mais e mais meninos e meninas "suam a camisa" nas ruas ou enfrentam a dura faina do campo. Batalham para ganhar o "pão nosso de cada dia" e sustentar um número crescente de famílias que sobrevivem à custa dos parcos tostôes provenientes da ocupação infantil. É o que estampam os jornais paranaenses ao longo dos anos de 1990.

Em Foz do Iguaçu, crianças e adolescentes são empregados na travessia de mercadorias "importadas" do Paraguai para o Brasil. "O 
pai está desempregado e tenho quatro irmãos menores. (...) aqui ganho até R\$30,00, por dia trazendo muamba", conta I.E.S., de 13 anos de idade ( $O$ Estado do Paraná, 24/8/1994).

Há meninos, a mando de traficantes, vendendo "trouxinhas" de cocaína nas entradas de favelas, ou meninas oferecendo-se para "programas” no centro da cidade. No campo a realidade não é menos cruel:

A mão-de-obra barata e até gratuita dos pequenos bóias-frias possibilita que agricultores e patrões em geral estimulem os pais a levar os menores como seus auxiliares. Na prefeitura de Santa Cruz do Monte Castelo, (...) $80 \%$ dos 10 mil habitantes viraram bóias-frias com a destruição das lavouras do café, substituídas pela pecuária dos anos 80 . O homem migrou do campo e ficou desempregado na cidade. A única alternativa é trabalhar temporariamente na colheita de algodão. Os filhos de qualquer idade ajudam a amealhar alguns preciosos reais que compõem o magro orçamento familiar. (Idem, ibid.)

Convém lembrar, como frisa o jornal, na mesma edição: o Estatuto da Criança e do Adolescente proíbe o trabalho de menores de 14 anos, salvo em condições especiais de aprendizado. "No entanto, essas regras não são respeitadas num país onde a fome perdura e a necessidade de conseguir o próprio sustento desde cedo se transforma em lei, por hábito e carência."

A realidade da exploração do trabalho mirim, em outras regiōes, nada fica a dever ao norte do estado. No Paraná, como um todo, $20 \%$ das crianças entre 10 e 13 anos trabalham "uma média bem acima dos padrões nacionais, mas bem próximo da situação nordestina, considerada uma das piores". Nas lavouras do estado, $37 \%$ de infantes acima de 10 anos labutam, havendo um número elevado dos que a partir de 5 anos desempenham atividades no campo. Ademais, 37\% perfazem 110 mil crianças, havendo fortes indícios de que este número esteja subestimado (Diário da Tarde, 10/10/1995).

Se o quadro por si só já é desolador, dados da Secretaria de Estado da Saúde revelam que "só em 1994 foram registrados 94\% de casos de intoxicação de menores de 18 anos, sendo 71 deles (18\%) por agrotóxicos", números que devem ser ainda maiores (Paraná/Conselho Estadual do Trabalho).

Há mais problemas de saúde assolando as crianças trabalhadoras do campo: perfuraçôes graves com mutilações permanentes e perda de membros; picadas de animais peçonhentos; insolaçóes; 
dermatoses; lesões por esforços repetitivos; lesões na coluna vertebral e artroses; problemas respiratórios, dentre outros (DIEESE, 2001). ${ }^{6}$

Embora fiscais do trabalho não tivessem constatado nos municípios paranaenses a utilização de crianças no plantio e corte de cana-de-açúcar e nas culturas de soja, milho e trigo, por se tratarem de culturas altamente mecanizadas, houve exploração da mão-deobra dos pequenos em outras lavouras. Algodão, batata e feijão foram trabalhados por infantes, assim como aquelas atividades típicas de cidade que passaram a se localizar em zonas rurais, tais como: olarias, serrarias, farinheiras, reflorestamento e extração de resinas ( $D i$ ário Popular, 8/6/1997).

"Só ganhamos do Piauí", lamentava o procurador-geral de Justiça do estado do Paraná, Olympio de Sá Sotto Maior, ao referir-se à exploração do trabalho infantil, principalmente nas áreas rurais, nas quais os filhos de agricultores começam muito cedo e em condiçôes muito insalubres.

A escola também se encontra vetada a esses infantes. As jornadas laborais dificilmente permitem a freqüência às aulas. Quando os horários são compatíveis, as crianças vão à escola, porém dificilmente têm tempo ou disposição para estudar, resultando em defasagem entre a idade e a série em curso.

O adolescente B.S.B. de 14 anos ilustra o quadro. Labuta no campo desde os 9. Começa a faina às 4 horas da manhã e deixa o serviço por volta das $17 \mathrm{~h}$, trabalhando para um "gato", que o transporta para roças de mandioca, onde recebe $\mathrm{R} \$ 8,00$ por dia. O menino utiliza enxada e, na escola, faz "correção de fluxo". "Parei na $4^{a}$ série do primário e estou tentando chegar na $8^{\mathrm{a}}$ ", diz ele (Gazeta do Povo, 14/10/1999). A escola noturna, levada a reboque dos afazeres, ocupa o tempo de descanso que o trabalho tomou.

Se a grande maioria das crianças se extenua no campo, há importante número delas nas cidades. Estudo do Instituto Paranaense de Desenvolvimento (IPARDES), em conjunto com o DIEESE e o SEADE-SP, realizado entre outubro de 1994 e setembro de 1995 , revelou que $26 \%$ de crianças (10 a 17 anos) compunham o mercado de trabalho na Região Metropolitana de Curitiba, equivalendo a 89 mil pessoas, assim distribuídas: $35,5 \%$ no setor de serviços; $22,1 \%$ no comércio; $17,5 \%$ na indústria; e $15,3 \%$ realizavam serviços domésticos. O salário percebido medianamente 
era de $\mathrm{R} \$ 126,00$ mensais e somente $53,4 \%$ dos menores tinham carteira assinada (O Estado do Paraná, 24/12/1995).

Vale lembrar: o Brasil tinha 3.289.262 crianças entre 10 e 14 anos trabalhando em 1995. Ano considerado aquele que concentraria os melhores efeitos da redistribuição da era pós-real, em razão do aumento efetivo do salário mínimo e da queda dos níveis inflacionários, o que redundaria, supostamente, em incremento da renda das famílias mais pobres (Cipola, 2001).

E mais, entre 1996 e 1999, não há mudanças significativas indicando que as ações institucionais contra o trabalho infantil tenham conseguido "alcançar uma redução na dimensão desse problema em escala nacional", mesmo com êxitos parciais como aponta a pesquisa realizada pela ONG carioca Núcleo de Assessoria Planejamento e Pesquisa - NAPP (Cipola, 2001, p. 56).

No centro da cidade de Curitiba, segundo pesquisa realizada pela Secretaria Municipal da Criança, 221 crianças trabalhavam em 1996. Destas, 84 vinham de municípios da Região Metropolitana e as atividades principais eram: esmoleiras $(31,2 \%)$; carregadores de sacola nas feiras (24\%); guardadores de carro (20,4\%); vendedores $(10,9 \%)$; engraxates $(9,9 \%)$; catadores de papel $(3,6 \%)$. Os meninos constituíam maioria $(71,5 \%)$ e $67 \%$ das crianças estudavam (Gazeta do Paraná, 14/5/1996). Embora o número total de crianças pareça bastante defasado, grosso modo, os porcentuais apontam o tipo de ocupação dos infantes, todos inseridos na economia informal e realizando sua labuta nas ruas da cidade.

A informalidade, a exemplo do início do século (Moraes, 1990), continua demarcando a ocupação dos pequenos a acompanhar o precário trabalho dos adultos.

Leis no entanto não faltam, na tentativa de dar um basta ao trabalho mirim. O Brasil, após contundentes denúncias realizadas por meio da imprensa, em fins da década de 1980, tem hoje na Constituição Federal, na Consolidação das Leis do Trabalho (CLT) e no Estatuto da Criança e do Adolescente (ECA), dispositivos regulamentares visando a impedir o "massacre dos inocentes", como denomina José de Souza Martins (1993), a exploração do trabalho dos pequenos.

Em 1996 foi lançado o Programa Nacional de Erradicação do Trabalho Infantil (PETI) nas carvoarias do Mato Grosso do Sul, destinando uma bolsa de $\mathrm{R} \$ 25,00$ para cada criança que os pais enviassem à escola ao invés de conduzirem-nas ao trabalho. 
Sim, pois exemplos e mais exemplos foram publicados e apresentados sobre as precárias condições de trabalho e vida dessas populaçôes. Em Maciço Florestal, por exemplo, área formada por quatro municípios, "famílias inteiras trabalhavam, em jornadas de 12 horas, recolhendo madeira que era empilhada por crianças de até 9 anos. Num dos fornos, uma menina de 4 anos estava ensacando carvão" (Sutton, 1994, p. 60).

O PETI ${ }^{8}$ chegou ao Paraná em 1997. O ministro do Trabalho esteve em Curitiba, oficializando o Fórum Estadual, coordenado pela Secretaria Estadual da Criança e Assuntos de Família. Foi selada parceria entre os governos federal, estadual e municipal e criado o programa "Da rua para a escola", que contempla com uma cesta básica por mês aquelas famílias cujos filhos deixassem o trabalho para entrar na escola (Gazeta do Povo, 8/7/1997). ${ }^{9}$

Colocadas muito cedo no mercado de trabalho, crianças deveriam estar estudando, para que na idade adulta pudessem ser bem aproveitadas em suas potencialidades, dizia o secretário de Segurança e Saúde do Ministério do Trabalho (Gazeta do Povo, 28/6/1997).

O trabalho infantil é: proibido por lei, deve ser fiscalizado e punido pelos governos, denunciado pela sociedade e por suas organizaçôes não-governamentais e impedido por empresas e sindicatos. Ora, por que se mantém como sangria desatada?

No Brasil, segundo o depoimento do procurador-geral de Justiça, Olympio de Sá Sotto Maior,

nossos trabalhadores de uma forma geral, e as crianças em particular, estão em situação pior que a dos antigos escravos. É que os trabalhadores de hoje são tratados como peças descartáveis, após terem sido explorados ao máximo, enquanto os escravos eram tratados como um capital a ser protegido. Isto é decorrência de um modelo econômico equivocado e cruel que faz com que tenhamos a sétima economia do mundo [sic] e que simultaneamente ocupemos a $64^{a}$. posição na distribuição de renda, ou que sejamos o quinto maior produtor mundial de alimentos, ao mesmo tempo que temos milhares de brasileiros passando fome. Por tudo isso, qualquer solução para o problema da existência de milhões de crianças trabalhando, em todo o Brasil, quando deveriam estar nos bancos escolares, passa necessariamente pela melhoria das condições econômicas, com a geração de mais empregos e a destinação de mais recursos para a área social. (Gazeta do Povo, 21/8/1997)

$\mathrm{Na}$ atual economia brasileira executam-se prescriçōes neoliberais. As receitas dos governos só conseguem aplicar paliativos às do- 
enças do corpo social - para não fugir às metáforas, tão ao gosto dos higienistas de antanho. As políticas compensatórias tentam "suprir" minimamente aquilo que o capital, em suas novas formas de organização do trabalho, retirou das classes laboriosas.

Se no fim do Novecentos muito nos distanciamos das normas higienizadoras preconizadas para as crianças pobres, lembremos: nos inícios do século os ditames da ciência apontavam alvissareiros avanços na escalada social para as classes populares, quando trabalhassem com afinco, entregando-se de corpo e alma ao sobreesforço redentor. A máxima do trabalho regenerador paulatinamente construída deitou marcas profundas na sociedade brasileira ao consolidar uma cultura do trabalho que permanece entranhada nos coraçóes e nas mentes dos despossuídos, às avessas do atual discurso de erradicação da labuta dos pequenos.

Junte-se, então: a situação de pobreza e desemprego dos pais à ineficiência do sistema educacional brasileiro - desinteressante e desfocado da realidade cotidiana dos explorados -, às perspectivas do trabalho "salvacionista" de tempos idos, que foi amalgamado na cultura popular laboriosa, e o que constatamos? A criança busca em sua ocupação a saída para a situação de penúria vivida. E mais, vislumbra a possibilidade de inserção social, já que outras lhe são negadas. Assim, não é por acaso que crianças sem infância preferem o trabalho à escola.

Exemplifiquemos com os meninos Antônio, de 15 anos, e Magnus, de 12, engraxates no Centro e Centro Cívico de Curitiba:

Com a mãe em casa cuidando dos quatro irmãos menores e o padrasto desempregado, Magnus é o único a levar dinheiro todos os dias para casa nos últimos dois meses. São cerca de $\mathrm{R} \$ 5,00$ por dia, podendo chegar a $\mathrm{R} \$ 8,00$ nos sábados e domingos de sol. Ele é engraxate desde os 6 anos de idade. O padrasto tem contribuído fazendo alguns "bicos", mas Magnus sente a responsabilidade. (Jornal do Estado, 21/8/2000)

"A gente está na luta porque quer e trabalha para não cair na bandidagem", diz Antônio, cujas preocupaçōes são "não bombear na escola, levar algum dinheiro para casa e escapar das kombis dos programas assistenciais dos governos municipal e estadual". ${ }^{10}$ A escola funciona como salvo-conduto para Antônio: trabalha mas também estuda, embora não pareça vislumbrar os propósitos dessa educação.

Inseridos na "roda viva" da exploração pelo trabalho, os infantes não terão as tais chances apregoadas. Formados na "escola-traba- 
lho da rua" (Cupertino, 1987), não estarão gabaritados para os postos hoje oferecidos. Despreparados para disputar uma vaga no mercado selvagem e competitivo, restar-lhes-á o subemprego, ou o mesmo desemprego que hoje assola seus pais. $O$ trabalho na infância terá substituído as atividades educativas que deveriam formá-lo cidadão. Cidadania hoje cobrada pelo mercado.

Assim, nas teias do mundo globalizado a educação do trabalhador assume características diferentes daquela preconizada no início do século. Na produção de base flexível, conhecimentos tecnológicos devem associar-se àqueles gerais, não cabendo mais repetição e subserviência à ordem. O velho aprendizado das disciplinas tão arduamente ensinado das Escolas de Artes e Ofícios, nas instituições de reforma e regeneração, nas quais os higienistas tanto se empenharam, defendendo o trabalho redentor, não atende aos desígnios do mercado atual. A criatividade, a avaliação, a análise crítica, a formação continuada e a iniciativa caracterizam os dispositivos normalizadores atuais, em substituição às práticas disciplinares de então. É o saber do trabalhador que lhe confere o poder para inserção no mercado. Só o "hábito do trabalho" não dá mais conta do recado.

As crianças que hoje labutam marginalizadas e estigmatizadas como "menores" não serão redimidas pelo trabalho que realizam. Ao mesmo tempo, a faina impedir-lhes-á de auferir a educação escolar hoje demandada. Assim o trabalho infantil salvacionista do início do século proposto pelos homens de ciência tornou-se o grande entrave dos futuros trabalhadores-cidadãos do século XXI. E mais, o discurso do trabalho higienizador cunhado e introjetado na cultura das classes desfavorecidas ainda permanece associado à miséria e exploração das crianças.

Jandirinha passou toda sua curta vida no lixo. Aos 8 anos ela é uma menina franzina, morena, muito ativa e esperta - sendo uma lixeira nata, é provável que saiba diferenciar uma lata num monturo de lixo mais rápido do que um detetor de metais. (...) Seu cabelo está sempre raspado para evitar piolhos. O guarda-roupa dela é catado ali mesmo - uma combinação sempre suja de casacos com mangas sobrando, calças duas vezes seu tamanho, chinelos dois números maiores que seu pezinho. (Gazeta do Povo, 1/5/2001)

A situação enfrentada por Jandira não é privilégio dela. Segundo dados do Programa Nacional de Erradicação do Trabalho Infantil (PETI), 647 crianças dependem dos lixões para viver em 47 cidades paranaenses, coletando recicláveis em aterros sanitários; destas, 
146 não freqüentavam a escola. Ressalte-se: neste cômputo ficaram de fora outras 352 cidades do estado. "Isto porque algumas prefeituras não querem admitir a existência do problema e outras nem se dignaram a contar seus pobres." Há mais 3.370 crianças catando lixo na rua, o que já virou "situação salutar", ante os catadores dos lixões, localizados principalmente em Paranaguá, Laranjeiras do Sul e Medianeira. O que esperar de um país cujas crianças sem infância, sem futuro e ditas "sementeiras da nação" catam lixo?

A cultura moral do trabalho para crianças miseráveis, cunhada nos reformatórios dos inícios do Novecentos, como forma de civilizálas e prepará-las para o futuro, extrapolou seus altos muros e ainda hoje compõe a mentalidade mirim. Vê-se que o "perigo" social e político representado pela miséria não foi debelado por meio do aprendizado da disciplina e das normas laborais preconizadas pelos homens da ciência da higiene. Ao contrário, a permanência do trabalho infantil que hoje ainda se escancara aos nossos olhos só tem forjado cidadãos de segunda categoria e a educação escolar permanece levada a reboque, o que vem reforçar o argumento: a higienização de crianças pobres pelo trabalho promoveu uma "normalização" às avessas do seu intento.

\section{Notas}

1. Medidas legislativas de proteção ao trabalho das crianças há muito não vinham sendo cumpridas. Margareth Rago chama a atenção para o Código Sanitário de 1894 que proibia o trabalho de menores de 12 anos no meio fabril, ou ainda o regulamento do Serviço Sanitário de 1911, que vetava o emprego de crianças com menos de 10 anos de idade ou o trabalho noturno aos menores de 18 anos (1987, p. 141).

2. Responsável pela formulação do conceito de criminoso nato a partir de medidas cranianas realizadas, Lombroso publica em 1876 a obra L'uomo delinqüente, na qual explica a predisposição natural para o crime existente em determinados indivíduos.

3. Leonídio Ribeiro explicaria a nova ciência nos Arquivos de Medicina Legal como destinada especialmente ao estudo das crianças difíceis e anormais. Por meio dela "será possível realizar a obra benemérita da profilaxia não só das doenças mentais como do próprio crime (...). As grandes linhas de reabilitação das crianças deformadas física ou moral devem ser, pois, traçadas dentro do quadro da medicina e da pedagogia" (apud Corrêa, in: Freitas, 1997, p. 78-79).

4 A Clínica de Eufrenia foi criada como “clínica de hábitos cujo público-alvo seriam dos lactentes às crianças de 12 anos de idade por meio de um contrato estabelecido entre a Prefeitura do Rio de Janeiro e a Liga Brasileira de Higiene Mental” (Schechtman, 1981).

5. Consultar Marisa Corrêa, in: Freitas, 1997.

6. Dados do diagnóstico médico realizado em 156 crianças que participaram do Encontro Nacional de Meninos e Meninas Trabalhadores Rurais, promovido pela CONTAG em 1996 (DIEESE, 2001, p. 188). 
7. Os pais carvoeiros normalmente põem os filhos no trabalho, pois ganham por empreitada e assim garantem melhor renda para a família. "Quando chega a idade de escolher uma profissão, o garoto não sabe nem ler - só sabe fazer forno e carvão" (Soares, 1999, p. 111).

8. O Programa Nacional de Erradicação do Trabalho Infantil (PETI) paranaense beneficia os municípios que montaram fóruns ou comissões para estudar o problema. Os jornais revelavam que as famílias cadastradas iriam receber $\mathrm{R} \$ 40,00$ mensais na área urbana e R\$25,00 em áreas rurais, "para retirarem os menores de 7 a 14 anos do trabalho, colocando-os na escola. Das 5.848 bolsas destinadas ao Estado, 3.239 são para a zona rural" (Jornal do Estado, 26 ago. 2000). Agradeço a Susan Ferst, monitora da disciplina de História da Educação, a pesquisa realizada na maioria dos jornais paranaenses.

9. Dados da Delegacia Regional Trabalho (DRT-PR) informavam que na área urbana eram 3.115 .207 pessoas de 10 anos ou mais economicamente ativas, sendo $75 \%$ de 10 a 14 anos e $7,63 \%$ de 15 a 17 anos. Na área rural, existiam 1.235 .694 pessoas de 10 anos ou mais economicamente ativas, sendo $12,26 \%$ de 10 a 14 anos e $10,12 \%$ de 15 a 17 anos (Gazeta do Povo, 8 jul. 1997).

10. “Eu já fui pego três vezes", diz Antônio que já avisou a moça: "Não adianta vir pra cima de mim de novo porque não vou entrar na kombi" (Jornal do Estado, 21 de agosto de 2000). A "moça da kombi" faz parte do quadro de "50 educadores e 15 assistentes sociais e pedagogos que circulam todas as noites em kombis nas regiões onde há maior concentração de menores trabalhadores. Eles questionam as crianças para saber o porquê de estarem na rua e a necessidade do dinheiro" (Jornal do Estado, 25 ago. 2000).

\section{Referências bibliográficas}

ANTONACCI, M.A.A.M. A vitória da razão: o Instituto de Organização Racional do Trabalho. 1986. 264f. Tese (Doutorado) - Departamento de História, Faculdade de Filosofia, Letras e Ciências Humanas, Universidade de São Paulo, São Paulo.

BERTUCCI, L.M. Saúde: arma revolucionária, São Paulo 1891/1925. Campinas: CMU; UNICAMP, 1997.

CIPOLA, A. O trabalho infantil. São Paulo: Publifolha, 2001. (Folha explica).

COSTA, J.F. História da psiquiatria no Brasil. 3. ed. Rio de Janeiro: Campus, 1981.

COSTA, J.F. Ordem médica e norma familiar. 3. ed. Rio de Janeiro: Graal, 1989.

CORRÊA, M. Antropologia e medicina legal: variaçōes em torno de um mito. In: Eulalıo, A. et al. Caminhos cruzados. São Paulo: Brasiliense, 1982. 
CORRÊA, M. A cidade de menores: uma utopia dos anos 30. In: Freitas, M.C. (Org.). História social da infância no Brasil. São Paulo: Cortez; Bragança Paulista: USF, 1997.

CUNHA, L.A. O ensino de ofícios nos primórdios da industrialização. São Paulo: UNESP; FLACSO, 2000.

CUNHA, M.C.P. O espelho do mundo: Juquery, a história de um asilo. Rio de Janeiro: Paz \& Terra, 1986.

DE BONI, M.I.M. Vigilância e punição: o espaço da criminalidade na constituição do trabalhador urbano; Curitiba 1890-1920. História: questôes e debates, Curitiba, v. 8, n. 14/15, p. 45-99, jul./dez. 1987.

DEL PRIORE, M. (Org). História das crianças no Brasil. 4.ed. São Paulo: Contexto, 1996.

DEL PRIORE, M. (Org.). História das crianças no Brasil. São Paulo: Contexto, 1999.

DEPARTAMENTO INTERSINDICAL DE ESTATISTICA E ESTUDOS SOCIO-ECONOMICOS. A situação do trabalho no Brasil. São Paulo: DIEESE, 2001.

KARVAT, E.C. A sociedade do trabalho: discursos e práticas de controle sobre a mendicidade e a vadiagem em Curitiba, 1890-1933. Curitiba: Aos Quatro Ventos, 1998.

LA BOÉTIE, E. Discurso da servidão voluntária. São Paulo: Brasiliense, 1987.

LEITE, E.M. O futuro do trabalho: novas tecnologias e subjetividade operária. São Paulo: Escrita, 1994.

MACHADO, R. et al. Da(n)ação da norma: medicina social e constituição da psiquiatria no Brasil. Rio de Janeiro: Graal, 1978.

MAIA, D. Regulamentação do trabalho. Rio de Janeiro: J. Silva, 1912.

MARQUES, V.R.B. A medicalização da raça: médicos, educadores e discurso eugênico. Campinas: UNICAMP, 1994.

MARTINS, J.S. Massacre dos inocentes: a criança sem infância no Brasil. 2. ed. São Paulo: Hucitec, 1993.

MELLO, F. Memória de um ex-escravo. In: . Trabalhadores. Campinas: Secretaria Municipal de Cultura, 1989. 
MIRANDA, B.T.M. Aspectos demográficos de uma cidade paranaense no século XIX: Curitiba, 1851-1880. 1978. Dissertação (Mestrado) - Departamento de História, Universidade Federal do Paraná, Curitiba.

MORAES, C.S.V. A socialização da força de trabalho: instrução popular e qualificação profissional no Estado de São Paulo, 1873-1934. 1990. 293f. Tese (Doutorado) - Faculdade de Filosofia, Letras e Ciências Humanas, Universidade de São Paulo, São Paulo.

MOURA, E.B.B. Trabalho feminino e condição social do menor em São Paulo (1890-1920). São Paulo: CEDHAL-USP, 1988.

PARANÁ. Conselho Estadual do Trabalho. Grupo temático sobre o trabatho infantil e do adolescente. Curitiba, 1995.

PARANÁ, S. Chorographia do Paraná. Curitiba: Typ. Liv. Economica, Annibal, Rocha \& cia, 1899.

PIRES, J.M. Trabalho infantil: a necessidade e a persistência. 1988. $310 f$. Dissertação (Mestrado) - Faculdade de Economia e Administração, Universidade de São Paulo, São Paulo.

RAGO, M. A utopia da cidade disciplina: Brasil 1890-1930. 2. ed. São Paulo: Paz \& Terra, 1987.

RAMOS, A. A criança problema: a higiene mental na escola primária. 4. ed. Rio de Janeiro: Casa do Estudante do Brasil, 1954.

ROCHA POMBO, J.F. O Paraná no centenário: 1500-1900. 2. ed. Rio de Janeiro: J. Olympio, 1930.

SCHECHTMAN, A. Psiquiatria e infância: um estudo hstórico sobre o desenvolvimento da psiquiatria infantil no Brasil. 1981. Dissertação (Mestrado) - Instituto de Medicina Social, Universidade do Estado do Rio de Janeiro, Rio de Janeiro.

SOARES, L. A vida na fornalha. Veja, São Paulo, 17 nov. 1999, p. 106-114.

TENCA, A. Razão e vontade política: o IDORT e a grande indústria dos anos 30. 1985. 130f. Dissertação (Mestrado) - Instituto de Filosofia e Ciências Humanas, Universidade Estadual de Campinas, Campinas.

WEINSTEIN, B. (Re)formação da classe trabalhadora no Brasil 19201964. São Paulo: Cortez; Bragança Paulista: USF, 2000. 
Fontes

Anais do I Congresso de Proteção à Infância

Revista Médica do Paraná

Diário da Tarde

Diário Popular

Folha do Paraná

Folha de S. Paulo

Gazeta do Paraná

Gazeta do Povo

Jornal do Estado

O Estado do Paraná 